\title{
Bone and Soft Tissue Blood Flow during Normobaric and Hyperbaric Oxygen Breathing in Healthy Divers
}

\author{
Agneta C. Larsson1,2, Johan Uusijärvi1,2, Jan E. Näslund1, Iréne Lund1, Peter Lindholm1,3 \\ ${ }^{1}$ Department of Physiology and Pharmacology, Karolinska Institute, Stockholm, Sweden \\ ${ }^{2}$ Department of Anaesthesia \& Intensive Care, Division of Hyperbaric Medicine, Karolinska Hospital, Stockholm, \\ Sweden \\ ${ }^{3}$ Department of Radiology, Karolinska Hospital, Stockholm, Sweden \\ Email: agneta.larsson@ki.se
}

Received 16 August 2014; revised 30 September 2014; accepted 14 October 2014

Copyright (C) 2014 by authors and Scientific Research Publishing Inc.

This work is licensed under the Creative Commons Attribution International License (CC BY).

http://creativecommons.org/licenses/by/4.0/

(c) (i) Open Access

\begin{abstract}
Purpose: The study aimed to investigate, using a photoplethysmographic (PPG) technique, how pulsatile blood flow within the patellar bone and skin over the patella reacts to normobaric (NBO) and hyperbaric oxygen breathing (HBO). Methods: Eleven healthy volunteers, breathed air or oxygen. Subjects were blinded to breathing gas. A range of partial pressures of oxygen were administered in 10 minute intervals: $21 \mathrm{kPa}, 101 \mathrm{kPa}$ (NBO), $21 \mathrm{kPa}$, (compression to $280 \mathrm{kPa}$ ), 59 $\mathrm{kPa}, 280 \mathrm{kPa}$ (HBO), $59 \mathrm{kPa}$, (decompression), and $21 \mathrm{kPa}$. Changes were measured continuously for each individual. Results: Hyperoxia decreased pulsatile patellar blood flow $\sim 32$ resp. 38\% and skin blood flow $\sim 36$ resp. $42 \%$ during the first 2 - 3 minutes of NBO resp. HBO. This decrease was normalized within 5 minutes after exposure. The results were similar when switching from air to NBO (101 kPa) and from air at pressure (59 kPa) to HBO $(280 \mathrm{kPa})$. Conclusions: The study shows that pulsatile patellar skin and bone blood flow, decreases significantly as a reaction to oxygen breathing in healthy subjects. The results suggest that a non-invasive PPG technique could be used to monitor blood flow changes in bone during oxygen treatment.
\end{abstract}

\section{Keywords}

Photopletysmography, Hyperbaric Oxygen, Bone, Osteomyelitis, Blood Flow

\section{Introduction}

Basic knowledge concerning blood flow regulation in bone tissue is lacking. Growth, remodelling and repair of

How to cite this paper: Larsson, A.C., Uusijärvi, J., Näslund, J.E., Lund, I. and Lindholm, P. (2014) Bone and Soft Tissue Blood Flow during Normobaric and Hyperbaric Oxygen Breathing in Healthy Divers. J. Biomedical Science and Engineering, 7, 973981. http://dx.doi.org/10.4236/ibise.2014.712094 
bone tissue require delivery of both nutrients and oxygen using blood flow as the pathway [1]. Disruption of normal bone blood flow has been shown to possibly be responsible for the development of both severe and common bone related diseases [2]. Most probably, there are vast differences in how and why blood flow is differently regulated in different parts of the skeleton [3].

A few facts are known about bone blood flow:

- Blood flow in bone is correlated to the position of the subject.

- The vascular organization in irregular and in flat bones differs significantly from that in long bones.

- The considerable periosteal blood supply present in flat bones is lacking in long bones [3].

- Bone blood flow is almost three times as high as the adjacent soft tissue blood flow [4].

- Bone blood flow is not proven to correlate to systemic blood pressure [5].

- Approximately $4 \%$ - $28 \%$ of the total cardiac output is estimated to be directed to bone blood flow [6].

Hemodynamic changes to hyperoxia in tissues other than bone have been extensively studied, but the underlying mechanisms are still far from completely understood [7]-[9]. Hyperoxia-mediated vasoconstriction and, as a result, decreased blood flow have been shown to occur in most healthy vascular beds in animals and man [10]. In the latter, this has been demonstrated in the brain, retina, myocardium, and in skeletal muscle. Vasodilatation in the microcirculation in some tissues has also been reported [11].

Hyperbaric oxygen (HBO) therapy has been shown to enhance bone turnover, to improve healing of infection in bone tissue, e.g. infectious complications after craniotomy or laminectomy [12], and also to improve healing after osteoradionecrosis [13]-[15], even though the exact mechanisms involved have not been entirely elucidated and the immediate reactions of HBO on bone blood flow have not been studied previously.

The physiologic effects of $\mathrm{HBO}$ are reported to have many different mechanisms including intravascular and tissue gas bubble reduction, improved tissue oxygenation, vasoconstriction, increased antimicrobial activity, modulation of inflammation and immune function, promotion of angiogenesis and the above mentioned increased bone turnover [16]. As the knowledge of which clinical protocol of HBO to use for best efficacy is not yet evaluated and there are known side-effects of HBO (mainly oxygen seizures), it is important to study the basic physiological reactions to HBO in humans. Lack of reliable and suitable methods for monitoring the oxygen content in target tissues makes evaluation and dosage of HBO difficult.

Presently, there has been no clinical non-invasive method available to evaluate oxygen content in bones, making it very difficult to follow the clinical progress of HBO treatment for i.e. osteomyelitis and osteoradionecrosis. Monitoring changes in bone blood flow during oxygen treatment could be of value in the study of physiological reactions related to HBO treatment.

In the present study a newly developed method, photoplethysmography (PPG), where changes in pulsatile blood flow within the patellar bone and overlying skin are recorded continuously is tested. PPG is a non-invasive optical technique and has been used to monitor blood flow in skin and muscles [17]-[19], but also to monitor hemodynamic sensing in implanted devices [20]. Furthermore, it has been used to study experimentally induced changes in pulsatile blood flow within the patellar bone [21]-[23]. However, the method has not yet been evaluated for hyperbaric use.

Oxygenation in target tissue is very difficult to measure non-invasively in humans, especially in bone tissue. There is a need for different techniques to evaluate the correct dose of oxygen to use to reverse ischemia in these tissues. The results of such information could possibly be used in the evaluation of the usefulness of oxygen therapies.

Our aim of the study was to examine whether the PPG technique could measure changes in blood flow of tissues that corresponded to changes in inhaled dose of oxygen. We therefore tested the technique in healthy subjects under extreme oxygenation of tissues (HBO). It was hypothesized that the PPG technique could be applied to detect pulsatile blood flow changes in skin and bone tissue of healthy subjects during their exposure to normobaric and hyperbaric hyperoxia. Whether or not the vascular system in the bone tissue would react in the same way as other vascular beds was not known.

\section{Methods}

\subsection{Subjects}

Eleven healthy non-smoking subjects (two females) were recruited from recreational divers to participate in the 
study. They were of mean age $30 \pm 4$ (mean/SD), height $177 \pm 9 \mathrm{~cm}$, weight $83 \pm 13$ and BMI $26 \pm 3$.

For one of the subjects, the PPG data was lost due to a technical error; this subject was therefore excluded from all analysis.

All subjects gave their written, informed consent to participate prior to the tests. The study was conducted in conformity with Ethical Principles for Medical Research Involving Human Subjects (World Medical Association Declaration of Helsinki, Geneva, 2000) and was approved by the Local Ethics Committee.

\subsection{Experimental Procedures}

Tests were performed in a hyperbaric multi-place chamber (Kockums, Sweden) using hoods (CASTAR, STARMed) supplied with either air or oxygen during the experiment. Throughout the experiment the subjects were blinded as to when they were breathing either air or oxygen. Subjects were positioned in a semi-recumbent position on a stretcher and the patellar PPG probe was attached and tested. The test protocol was started after a further 10 minutes of rest.

All test were done in the afternoon or evening.

Different $\mathrm{O}_{2}$ partial pressures were administered in the following 10 minute intervals:

Normobaric: $21 \mathrm{kPa}$ (air), $101 \mathrm{kPa}\left(100 \% \mathrm{O}_{2}\right)$ and $21 \mathrm{kPa}$ (Figure 1).

Hyperbaric: (compression to $280 \mathrm{kPa}$ ), $59 \mathrm{kPa}$ (air), $280 \mathrm{kPa}\left(100 \% \mathrm{O}_{2}\right), 59 \mathrm{kPa}$, (decompression to $21 \mathrm{kPa}$ including a safety stop at $130 \mathrm{kPa}$ for 5 minutes) (Figure 2).

The chamber was ventilated to hold an environmental temperature of $20^{\circ} \mathrm{C}-25^{\circ} \mathrm{C}$.

\subsection{Measurements}

A two channel PPG instrument (Department of Biomedical Engineering, Linköping University, Sweden) and a PPG probe were used to continuously record blood flow changes in the patellar bone and in the skin overlying the patella. The probe uses near-infrared light sources (bone $804 \mathrm{~nm}$ and skin $560 \mathrm{~nm}$ ). The method has previously been used for measurements of blood flow in patella [21].

The PPG probe was fastened on the skin over the left patella using adhesive tape, and a green coloured cover was placed on top to minimize the influence of ambient light. The probe was connected with the PPG instrument outside the chamber by a pass-through in the chamber wall.

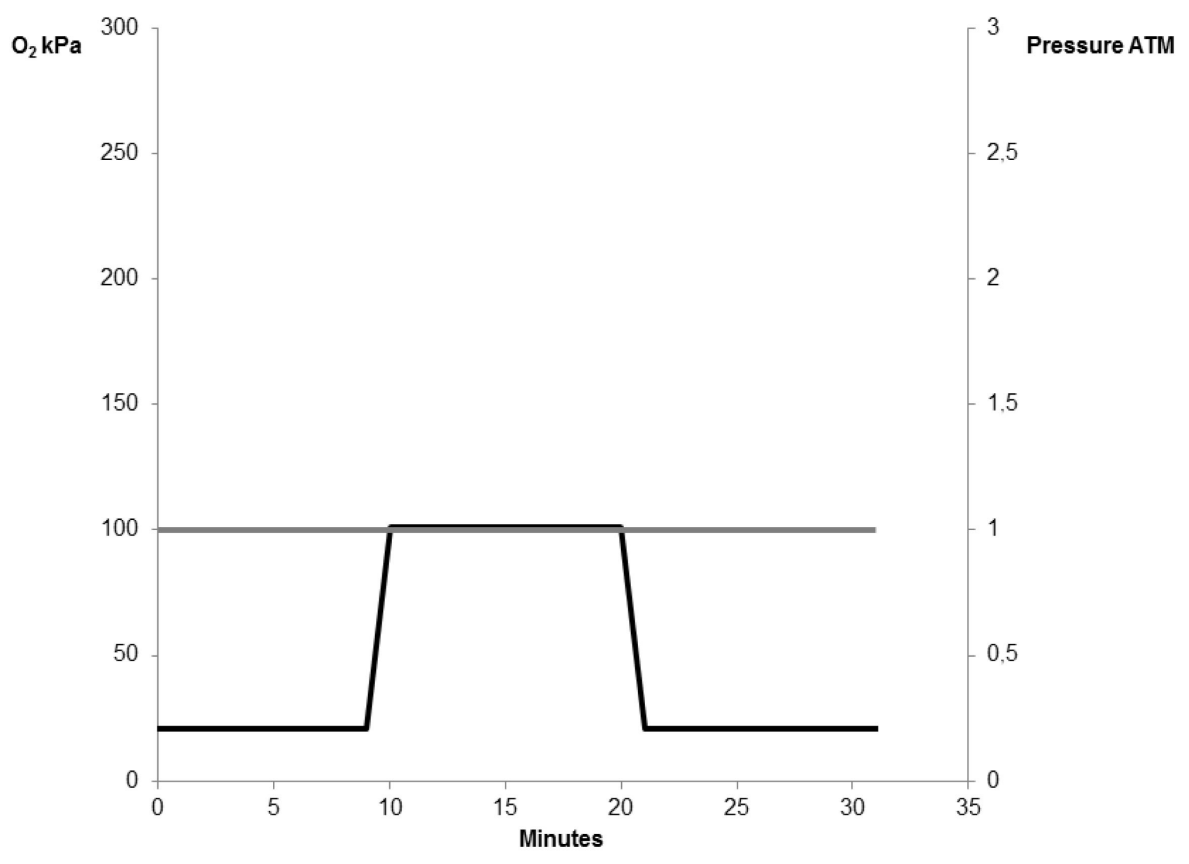

Figure 1. NBO, atmospheric pressure described in ATM right axis, grey line, oxygen breathing pressure for volunteers in $\mathrm{kPa}$ left axis, black line. Time in minutes. 


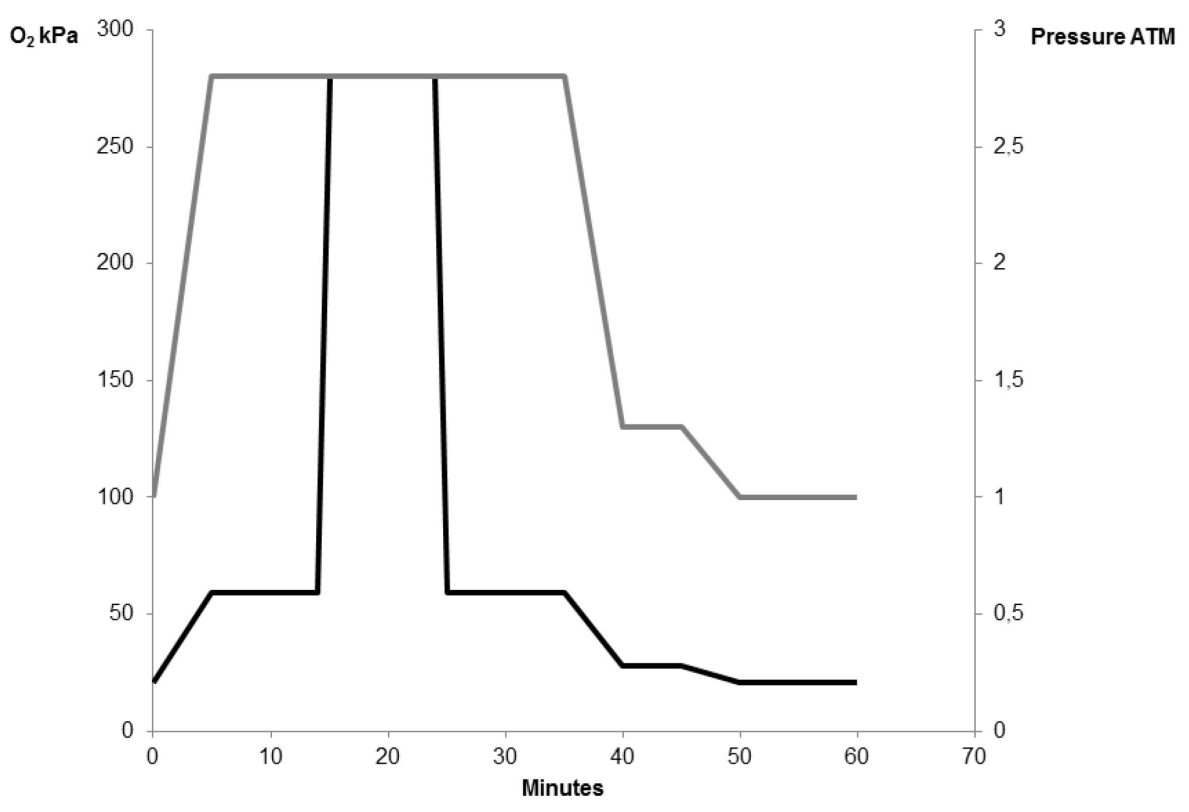

Figure 2. HBO, atmospheric pressure described in ATM right axis, grey line, oxygen breathing pressure for volunteers in $\mathrm{kPa}$ left axis, black line. Time in minutes.

The pulse-by-pulse amplitude of the AC component of the PPG signal was subsequently extracted with dedicated software (Daquhura 1.3, Linköpings Tekniska Högskola 1995). The analysing software gave simultaneous recordings.

The PPG signal was later analysed using software (MATLAB, R2006b). A base-line, pre-oxygen value was calculated from a period of 30 - 60 seconds peak-to-peak recordings, both during normobaric and hyperbaric conditions. When the bone blood flow was recorded at its lowest level, after 2 min, another period of 30 seconds peak-to-peak recording was calculated and used as oxygen breathing value.

Differences in individual data of assessments in pulsatile bone and skin blood flow were expressed as percentage of change between air breathing and NBO/HBO respectively, as calibration is a limit.

\subsection{Statistics}

Mean values and standard deviation (SD) were calculated for quantitative, continuous data such as age, height, weight. Blood flow changes were expressed as percentage of the pre-oxygen level and were presented as mean (95\% confidence interval). T-test for dependent samples was used to analyse blood flow changes. The level of significance was set at $\mathrm{P}<0.05$.

The statistical package Statistica 10.0 (StatSoft Inc., Tulsa, USA) was used for descriptive statistics and statistical analysis.

\section{Discussion}

\subsection{Results}

Both during the initiation of NBO and HBO, the patellar and skin pulsatile blood flow decreased during the first three minutes of oxygen breathing (Figure 3). Blood flow returned to base-line levels within 5 - 8 minutes (data not shown).

When switching from air to oxygen breathing during NBO, both the bone blood flow decreased, $-32 \%$ (95\% CI, -21 to -42$)$, as did the skin blood flow $-36 \%$ (95\% CI -24 to -48$)$. The pattern of change in blood flow during $\mathrm{HBO}$ was seen as a decrease in bone blood flow, $-38 \%(95 \% \mathrm{CI}-22$ to -54$)$ and also in the skin, $-42 \%$ (95\% CI -26 to -58) (Figure 4). Irrespective of NBO or HBO, a similar pattern of changes were seen in blood flow in both tissues. No systematic differences were found between the two experimental situations when comparing the percentage change. 


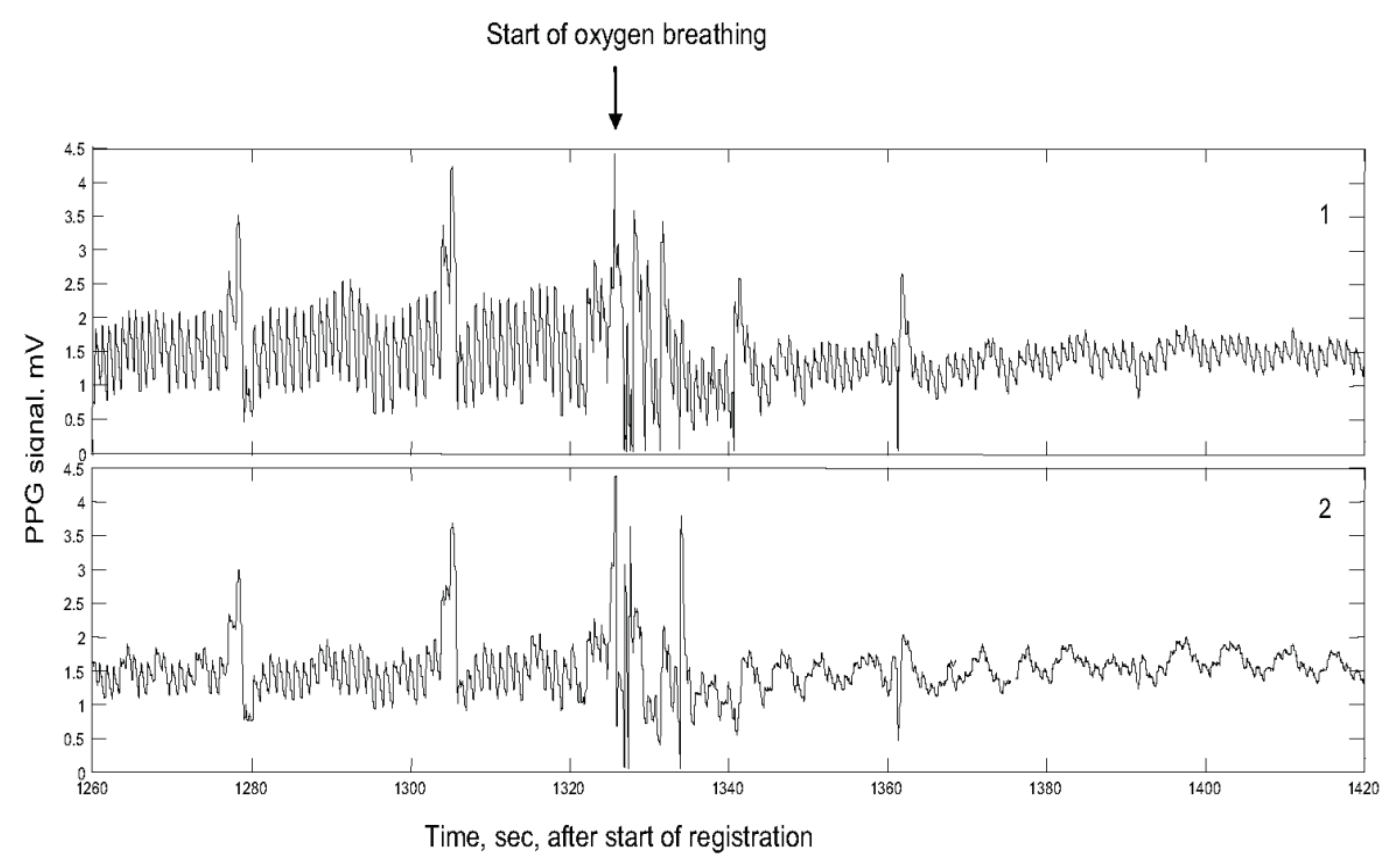

Figure 3. PPG recording during HBO therapy in subject 4, showing blood flow changes in (1) bone, (2) skin.

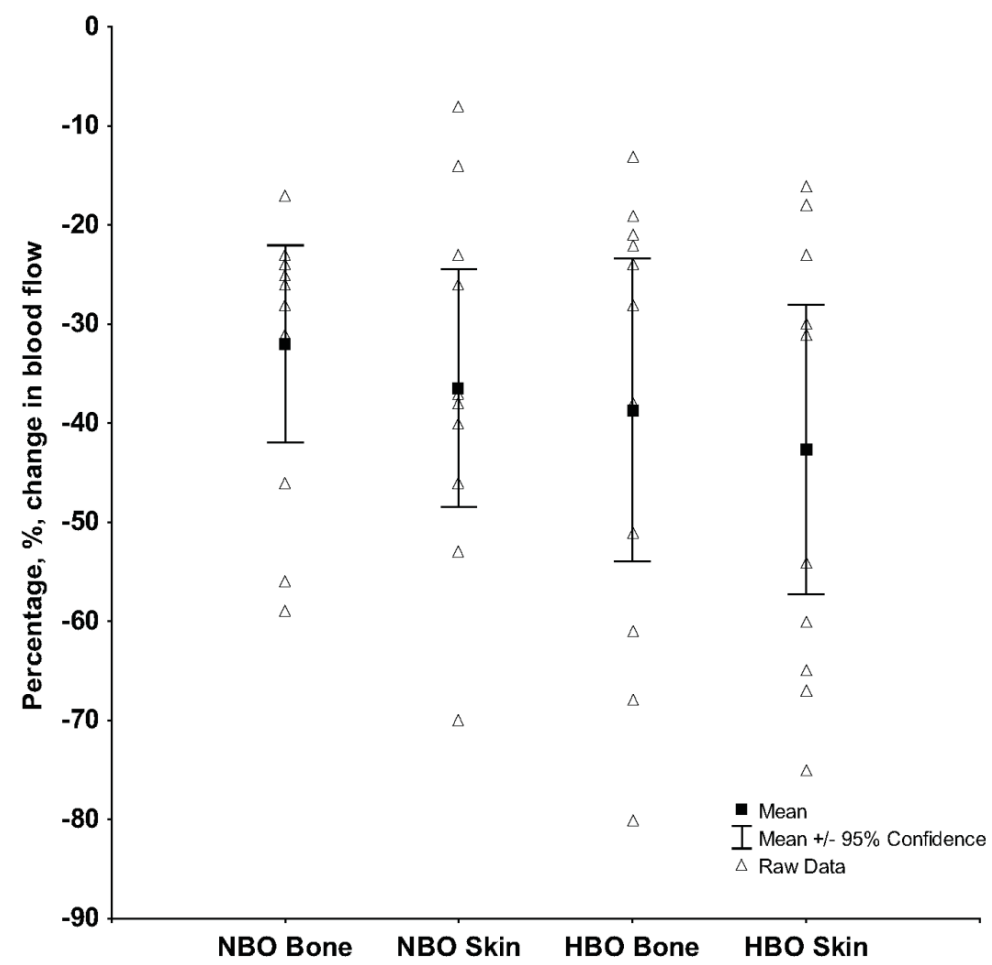

Figure 4. Percentage change in bone and skin blood flow during the first 2 - 3 minutes of NBO and HBO respectively. 0 in the figure represents our initial calibration point from which changes were measured, not a zero-point for blood flow of the subjects.

\subsection{Bone Blood Flow}

Hypoxia is one of the possible regulators of microcirculation in bone tissue. Shim and Peterson [5] observe that 
this metabolic control mechanism is the most potent regulator of bone blood flow in rabbits. They note that blood flow appears to be closely related to oxygen and carbon dioxide tension, $\mathrm{pH}$, and acid metabolites. In addition Brookes \& Revell [3] propose that local acidosis provides a stimulus for bone accumulation, and Gross et al. [24] hypothesize that hypoxia is responsible for bone vaso regulation. These statements are in accordance with our results, measuring hyperoxia, which showed that changes in tissue oxygen levels had an impact on pulsatile bone blood flow.

Blood flow in most tissues is influenced by activity. In the present study, a 10 minute resting period before exposure was used [25]. Since we do not yet know the correct resting time to down-regulate bone blood flow to base-line values, the 10 minute period may have been too short. In the future it would also be of great interest to study the correct resting-time and compare blood flow in healthy bone to blood flow in bone with some of the disorders where $\mathrm{HBO}$ is currently used as an adjunctive treatment.

\subsection{HBO}

Studies in rats and humans show that exposure to HBO causes a general, quick vasoconstriction and blood flow reduction in various organs [9] [26].

Several possibilities are discussed as mechanisms causing the vasoconstriction: i.e. reactive $\mathrm{O}_{2}$ species inhibit vasodilatation; the superoxide anion is an endothelium derived contracting factor [27] and endothelin-1 concentration increases during HBO [28]. Another possibility may be that arterioles adjust their diameter and resistance to maintain constant delivery of oxygen. The increased $\mathrm{PO}_{2}$ at 2.8 ATA increases dissolved $\mathrm{O}_{2}$ in the blood. Maintaining a constant delivery of oxygen, a decrease in flow through a reduction of diameter of the arterioles would be expected. Vucetic et al. [29] reports an overall reduction in human retina arteriole diameter of $10 \%$ after 10 min HBO (2.5 ATA), which corresponds with a $40 \%$ fall in blood flow.

HBO exposure induces an early cerebral vasoconstriction in mice due to inactivation of eNOS-derivated NO, and is then followed by a late vasodilatation [30]. This late cerebral vasodilatation during HBO exposure could be due to differences in HBO profile (i.e. pressure and exposure time), the different vessels and species used in the studies, or the fact that studies have focused on either early or late reactions to HBO [9]. Responses in rat and human cells, or tissues, to HBO might not be comparable, although rat and human circulatory physiology are very similar. In addition, one might argue that reactions to hyperoxia probably are quite different in pathological tissues.

The effect of HBO on cerebral blood flow is however, found to be highly dependent on the monitoring method, since other studies reveale no such systematic changes [31]. Microcirculatory brain blood flow in rats decreases significantly in the first few minutes after HBO but returns to baseline levels within a variable period, still under HBO [11]. This finding is supported by our results showing decreased blood flow initially.

HBO is known to have a large influence on the cardiovascular system. Systolic blood pressure increases and diastolic pressure falls. Peripheral resistance increases by about 30\%, while heart frequency and cardiac output fall by approximately 20\% [32] [33]. In an earlier study, we measured blood pressure and heart rate using the same HBO protocol and likewise found that heart rate decreased when switching from air to NBO (from 62 to 58 beats/min) but also decreased when switching from air at pressure to HBO (from 60 to 54). However, mean arterial pressure did not change significantly when switching from air to NBO and when switching pressurized air to HBO in healthy subjects [34].

It is reported that hyperoxia causes a decrease of blood flow in resting and contracting muscles [35], Iida et al. [36] finds that ischemic bone marrow disorders such as osteonecrosis in the knee are likely to develop in areas with lower blood volume. In bone, ischemia sometimes stimulates remodelling and neovascularization. It is shown that exposure to intermittent normobaric hypoxia results in distinct tissue remodelling [37] [25]. Prolonged ischemia may cause cell death, and ischemia is reported to be responsible for osteonecrosis [38]. Obviously, there is a need for studies on bone blood flow in order to understand some common bone related disorders.

Neither the clinical indications for HBO therapy nor the correct protocols of HBO to be used for most clinical indications have yet been proved. Theories of the paradoxal vasoconstriction measured in healthy tissues by oxygen include a threshold level of oxygen where vasoconstriction changes to vasodilatation, changed regulatory mechanisms in unhealthy compared to healthy tissues and physiologically local changes in blood flow to tissues. Monitoring changes close to the diseased tissue could help both to understand and develop correct HBO 
protocols. The lack of reliable and suitable monitoring methods of oxygen content in the target tissues makes evaluation and dosage of the method difficult.

PPG monitoring may add some data to the decision process. Often treatment protocols of 60 - 120 minutes of oxygen breathing, interrupted by 5 - 10 minutes of air at a pressure of $2.0-2.8$ ATA are seen. The choice of protocol is often based on local tradition.

We propose that the PPG method could be used to monitor changes in blood flow, and therefore add important information in studies on doses and effects of HBO.

\subsection{PPG}

An important limitation of the present PPG technique is the lack of a gold standard for calibration. Therefore, at present results from PPG measurements can only be reported as changes from one point in time to another. In a review Allen [19] discusses the validity and reliability of PPG measurements. For basal perfusion of the microcirculation, the amplitude of the PPG pulse correlates with Laser Doppler blood flow. Also, there are only few studies quantifying the repeatability or reproducibility of PPG measurements. An averaging period covering at least 30 - 60 heartbeats is suggested to improve confidence in PPG pulse measurements [19], and this time period was used in our study. For further discussions on validation of the PPG method see Hagblad et al. [39] and Näslund et al. [23].

Using a PPG method we have reported decreased blood flow in bone and skin tissues after NBO and HBO exposure. For skin, this is in accordance with studies using the Laser Doppler technique [11] [40].

The similar results in many studies using different measuring methods indicate that decreased blood flow is a valid immediate reaction in skin to increasing oxygen pressure and subsequent oxygen tissue saturation in healthy subjects, but also indicate that it is possible to use the PPG technique during hyperbaric conditions. With Laser Doppler it is shown that changes occurring immediately after increasing oxygen levels are due to changes in the hemodynamic responses tending towards vasoconstriction [11]. Since it is shown that the PPG method for blood flow measurements is equal to both Laser Doppler as well as Ultrasound in detecting blood flow changes down to a depth of $23 \mathrm{~mm}$ [39] we conclude that using the PPG method it is possible to study blood flow changes in relation to NBO and HBO both in skin and patellar bone (804 nm for patellar bone and $560 \mathrm{~nm}$ for skin). This is supported by Näslund et al. [21] where it is shown that experimentally induced arterial occlusion and venous stasis is detectable in the patellar bone using the PPG method.

Prior to the use of PPG monitors for clinical practice under hyperbaric conditions, further tests are necessary to ensure a safe and accurate use. There are, to our knowledge, not yet any commercially available PPG monitors for hyperbaric use.

\section{Conclusions}

PPG can be used to monitor dynamic changes in bone blood flow during both normobaric and hyperbaric oxygen breathing. Bone blood flow showed a temporary decrease when $\mathrm{PO}_{2}$ increased, during both normobaric and hyperbaric oxygenation in healthy recreational divers.

The marked changes in blood flow during normobaric hyperoxia suggest that further methodological studies on this reaction should be evaluated.

\section{Acknowledgements}

Stockholm City Council has supported this study.

\section{Conflict of Interest}

The authors declare that they have no conflict of interest.

\section{Ethical Consideration}

The study has been approved by the local ethics committee.

\section{References}

[1] Brinker, M.R., Lippton, H.L., Cook, S.D. and Hyman, A.L. (1990) Pharmacological Regulation of the Circulation of 
Bone. The Journal of Bone and Joint Surgery, 72A, 964-975.

[2] Frost, M.L., C.G., Blake, G.M., Marsden, P.K., Benatar, N.A. and Fogelman, I. (2003) A Prospective Study on Regional Bone Metabolism and Blood Flow at the Lumbar Spine Measured by 18F Fluoride Positron Emission Tomography. Journal of Bone and Mineral Research, 18, 2215-2222. http://dx.doi.org/10.1359/jbmr.2003.18.12.2215

[3] Brookes, M.R.W. (1998) Blood Supply of Bone. Springer, London. http://dx.doi.org/10.1007/978-1-4471-1543-4

[4] Dayan, L., Keidar, Z., Israel, O., Milloul, V., Sachs, J. and Jacob, G. (2008) SPECT/CT-Plethysmography-Non-Invasive Quantitation of Bone and Soft Tissue Blood Flow. Journal of Orthopaedic Surgery and Research, 3, 36. http://dx.doi.org/10.1186/1749-799X-3-36

[5] Shim, S.S., Copp, D.H. and Patterson, F.P. (1967) An Indirect Method of Bone Blood-Flow Measurement Based on the Bone Clearance of a Circulating Bone-Seeking Radioisotope. The Journal of Bone and Joint Surgery, 49, 693-702.

[6] Gross, P.M., Marcus, M.L. and Heistad, D.D. (1981) Measurement of Blood Flow to Bone and Marrow in Experimental Animals by Means of the Microsphere Technique. The Journal of Bone and Joint Surgery, 63, 1028-1031.

[7] Stuhr, L.E., Bergo, G.W. and Tyssebotn, I. (1994) Systemic Hemodynamics during Hyperbaric Oxygen Exposure in Rats. Aviation, Space, and Environmental Medicine, 65, 531-538.

[8] Bergo, G.W. and Tyssebotn, I. (1995) Effect of Exposure to Oxygen at 101 and $150 \mathrm{kPa}$ on the Cerebral Circulation and Oxygen Supply in Conscious Rats. European Journal of Applied Physiology and Occupational Physiology, 71, 475-484. http://dx.doi.org/10.1007/BF00238548

[9] Hink, J., Thom, S.R., Simonsen, U., Rubin, I. and Jansen, E. (2006) Vascular Reactivity and Endothelial NOS Activity in Rat Thoracic Aorta during and after Hyperbaric Oxygen Exposure. American Journal of Physiology, Heart and Circulatory Physiology, 291H, 1988-1998. http://dx.doi.org/10.1152/ajpheart.00145.2006

[10] Rousseau, A., Steinwall, I., Woodson, R.D. and Sjoberg, F. (2007) Hyperoxia Decreases Cutaneous Blood Flow in High-Perfusion Areas. Microvascular Research, 74, 15-22. http://dx.doi.org/10.1016/j.mvr.2007.02.001

[11] Meirovithz, E., Sonn, J. and Mayevsky, A. (2007) Effect of Hyperbaric Oxygenation on Brain, Emodynamics, Hemoglobin Oxygenation and Mitochondrial NADH. Brain Research Reviews, 54, 294-304. http://dx.doi.org/10.1016/j.brainresrev.2007.04.004

[12] Larsson, A., Engstrom, M., Uusijarvi, J., Kihlstrom, L., Lind, F. and Mathiesen, T. (2008) Hyperbaric Oxygen Treatment of Postoperative Neurosurgical Infections. Neurosurgery, 62, 652-671. http://dx.doi.org/10.1227/01.neu.0000316260.67220.cf

[13] Marx, R.E. (2007) Bone and Bone Graft Healing. Oral and Maxillofacial Surgery Clinics of North America, 19, 455466. http://dx.doi.org/10.1016/j.coms.2007.07.008

[14] Marx, R.E., Ehler, W.J., Tayapongsak, P. and Pierce, L.W. (1990) Relationship of Oxygen Dose to Angiogenesis Induction in Irradiated Tissue. The American Journal of Surgery, 160, 519-524. http://dx.doi.org/10.1016/S0002-9610(05)81019-0

[15] Granström, G., Tjellström, A. and Brånemark, P.I. (1999) Osseointegrated Implants in Irradiated Bone: A Case-Controlled Study Using Adjunctive Hyperbaric Oxygen Therapy. Journal of Oral and Maxillofacial Surgery, 57, 493-499. http://dx.doi.org/10.1016/S0278-2391(99)90059-9

[16] Edwards, M.L. (2010) Hyperbaric Oxygen Therapy. Part 2: Application in Disease. Journal of Veterinary Emergency and Critical Care, 20, 289-297. http://dx.doi.org/10.1111/j.1476-4431.2010.00535_1.x

[17] Kamal, A.A., Harness, J.B., Irving, G. and Mearns, A.J. (1989) Skin Photoplethysmography-A Review. Computer Methods and Programs in Biomedicine, 28, 257-269. http://dx.doi.org/10.1016/0169-2607(89)90159-4

[18] Zhang, Q., Lindberg, L.G., Kadefors, R. and Styf, J. (2001) A Non-Invasive Measure of Changes in Blood Flow in the Human Anterior Tibial Muscle. European Journal of Applied Physiology, 84, 448-452. http://dx.doi.org/10.1007/s004210100413

[19] Allen, J. (2007) Photoplethysmography and Its Application in Clinical Physiological Measurement. Physiological Measurement, 28, R1. http://dx.doi.org/10.1088/0967-3334/28/3/R01

[20] Turcott, R.G. and Pavek, T.J. (2008) Hemodynamic Sensing Using Subcutaneous Photoplethysmography. American Journal of Physiology, Heart and Circulatory Physiology, 295, H2560-H2572.

http://dx.doi.org/10.1152/ajpheart.00574.2008

[21] Näslund, J., Pettersson, J., Lundeberg, T., Linnarsson, D. and Lindberg, L.G. (2006) Non-Invasive Continuous Estimation of Blood Flow Changes in Human Patellar Bone. Medical \& Biological Engineering \& Computing, 44, 501-509. http://dx.doi.org/10.1007/s11517-006-0070-0

[22] Näslund, J., Waldén, M. and Lindberg, L.G. (2007) Decreased Pulsatile Blood Flow in the Patella in Patellofemoral Pain Syndrome. The American Journal of Sports Medicine, 35, 1668-1673.

http://dx.doi.org/10.1177/0363546507303115 
[23] Näslund, J.E., Näslund, S., Lundeberg, T., Linnarsson, D., Lindberg, L.G. and Lund, I. (2011) Bone Blood Flow Is Influenced by Muscle Contractions. Journal of Biomedical Science and Engineering, 4, 490-496. http://dx.doi.org/10.4236/jbise.2011.47062

[24] Gross, P.M., Heistad, D.D. and Marcus, M.L. (1979) Neurohumoral Regulation of Blood Flow to Bones and Marrow. The American Journal of Physiology, 237, H440-H448.

[25] Colleran, P.N., Wilkerson, M.K., Bloomfield, S.A., Suva, L.J., Turner, R.T. and Delp, M.D. (2000) Alterations in Skeletal Perfusion with Simulated Microgravity: A Possible Mechanism for Bone Remodeling. Journal of Applied Physiology, 89, 1046-1054.

[26] Hansen, M., Jacobsen, E. and Madsen, J. (1976) Influence of Hypoxia and Hyperoxia on Subcutaneous Adipose Tissue Blood Flow in Man. Scandinavian Journal of Clinical Laboratory Investigation, 36, 655-660.

[27] Katusic, Z.S. and Vanhoutte, P.M. (1989) Superoxide Anion Is an Endothelium-Derived Contracting Factor. The American Journal of Physiology, 257, H33-H37.

[28] Rocco, M., Antonelli, M., Letizia, V., Alampi, D., Spadetta, G., Passariello, M., Conti, G., Serio, P. and Gasparetto, A (2001) Lipid Peroxidation, Circulating Cytokine and Endothelin 1 Levels in Healthy Volunteers Undergoing Hyperbaric Oxygenation. Minerva Anestesiologica, 67, 393-400.

[29] Vucetic, M., Jensen, P.K. and Jansen, E.C. (2004) Diameter Variations of Retinal Blood Vessels during and after Treatment with Hyperbaric Oxygen. The British Journal of Ophthalmology, 88, 771-775. http://dx.doi.org/10.1136/bjo.2003.018788

[30] Atochin, D.N., Demchenko, I.T., Astern, J., Boso, A.E., Piantadosi, C.A. and Huang, P.L. (2003) Contributions of Endothelial and Neuronal Nitric Oxide Synthases to Cerebrovascular Responses to Hyperoxia. Journal of Cerebral Blood Flow and Metabolism, 23, 1219-1226. http://dx.doi.org/10.1097/01.WCB.0000089601.87125.E4

[31] Thom, S.R., Bhopale, V., Fisher, D., Manevich, Y., Huang, P.L. and Buerk, D.G. (2002) Stimulation of Nitric Oxide Synthase in Cerebral Cortex Due to Elevated Partial Pressures of Oxygen: An Oxidative Stress Response. Journal of Neurobiology, 51, 85-100. http://dx.doi.org/10.1002/neu.10044

[32] Oriani, G., Marroni, A. and Wattel, F. (1996) Handbook of Hyperbaric Medicine. Springer, Berlin. http://dx.doi.org/10.1007/978-88-470-2198-3

[33] Jain, K. (1999) Textbook of Hyperbaric Medicine. H \& H.

[34] Larsson, A., Uusijärvi, J., Eksborg, S. and Lindholm, P. (2010) Tissue Oxygenation Measured with Near-Infrared Spectroscopy during Normobaric and Hyperbaric Oxygen Breathing in Healthy Subjects. European Journal of Applied Physiology, 109, 757-761. http://dx.doi.org/10.1007/s00421-010-1403-0

[35] Pedersen, P.K., Kiens, B. and Saltin, B. (1999) Hyperoxia Does Not Increase Peak Muscle Oxygen Uptake in Small Muscle Group Exercise. Acta Physiologica Scandinavica, 166, 309-318. http://dx.doi.org/10.1046/j.1365-201x.1999.00575.x

[36] Iida, S., Harada, Y., Ikenoue, S. and Moriya, H. (1999) Measurement of Bone Marrow Blood Volume in the Knee by Positron Emission Tomography. Journal of Orthopaedic Science, 4, 216-222. http://dx.doi.org/10.1007/s007760050096

[37] Zhen, G., Zhang, Z. and Xu, Y. (2003) The Role of Endogenous Carbon Monoxide in the Hypoxic Vascular Remodeling of Rat Model of Hypoxic Pulmonary Hypertension. Journal of Huazhong University of Science and Technology, 23, 356-368.

[38] Hughes, S.S., Cammarata, A., Steinmann, S.P. and Pellegrini Jr., V.D. (1998) Effect of Standard Total Knee Arthroplasty Surgical Dissection on Human Patellar Blood Flow in Vivo: An Investigation Using Laser Doppler Flowmetry. Journal of the Southern Orthopaedic Association, 7, 198-204.

[39] Hagblad, J., Lindberg, L.G., Andersson, A.K., Bergstrand, S., Lindgren, M., Ek, A.C., Folke, M. and Linden, M. (2010) A Technique Based on Laser Doppler Flowmetry and Photoplethysmography for Simultaneously Monitoring Blood Flow at Different Tissue Depths. Medical \& Biological Engineering \& Computing, 48, 415-422. http://dx.doi.org/10.1007/s11517-010-0577-2

[40] Stirban, A., Lentrodt, S., Nandrean, S., Pop, A., Tschoepe, D. and Scherbaum, W.A. (2009) Functional Changes in Microcirculation during Hyperbaric and Normobaric Oxygen Therapy. Undersea \& Hyperbaric Medicine: Journal of the Undersea and Hyperbaric Medical Society, Inc, 36, 381-390. 
Scientific Research Publishing (SCIRP) is one of the largest Open Access journal publishers. It is currently publishing more than 200 open access, online, peer-reviewed journals covering a wide range of academic disciplines. SCIRP serves the worldwide academic communities and contributes to the progress and application of science with its publication.

Other selected journals from SCIRP are listed as below. Submit your manuscript to us via either submit@scirp.org or Online Submission Portal.
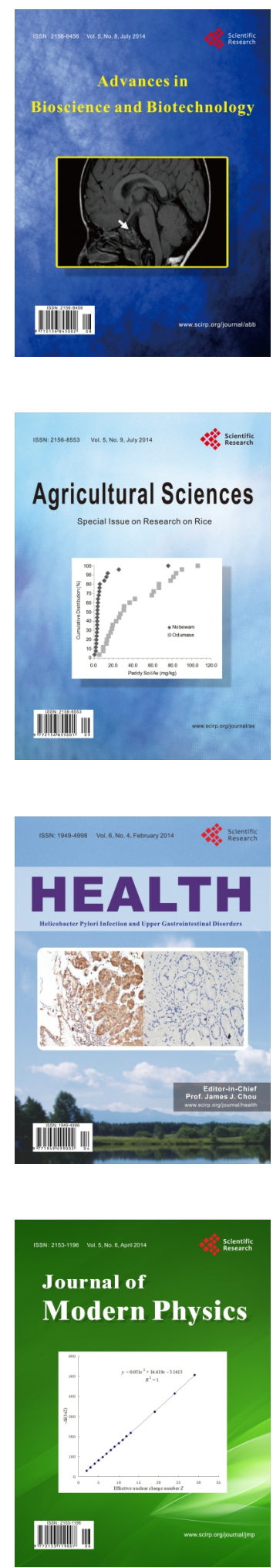
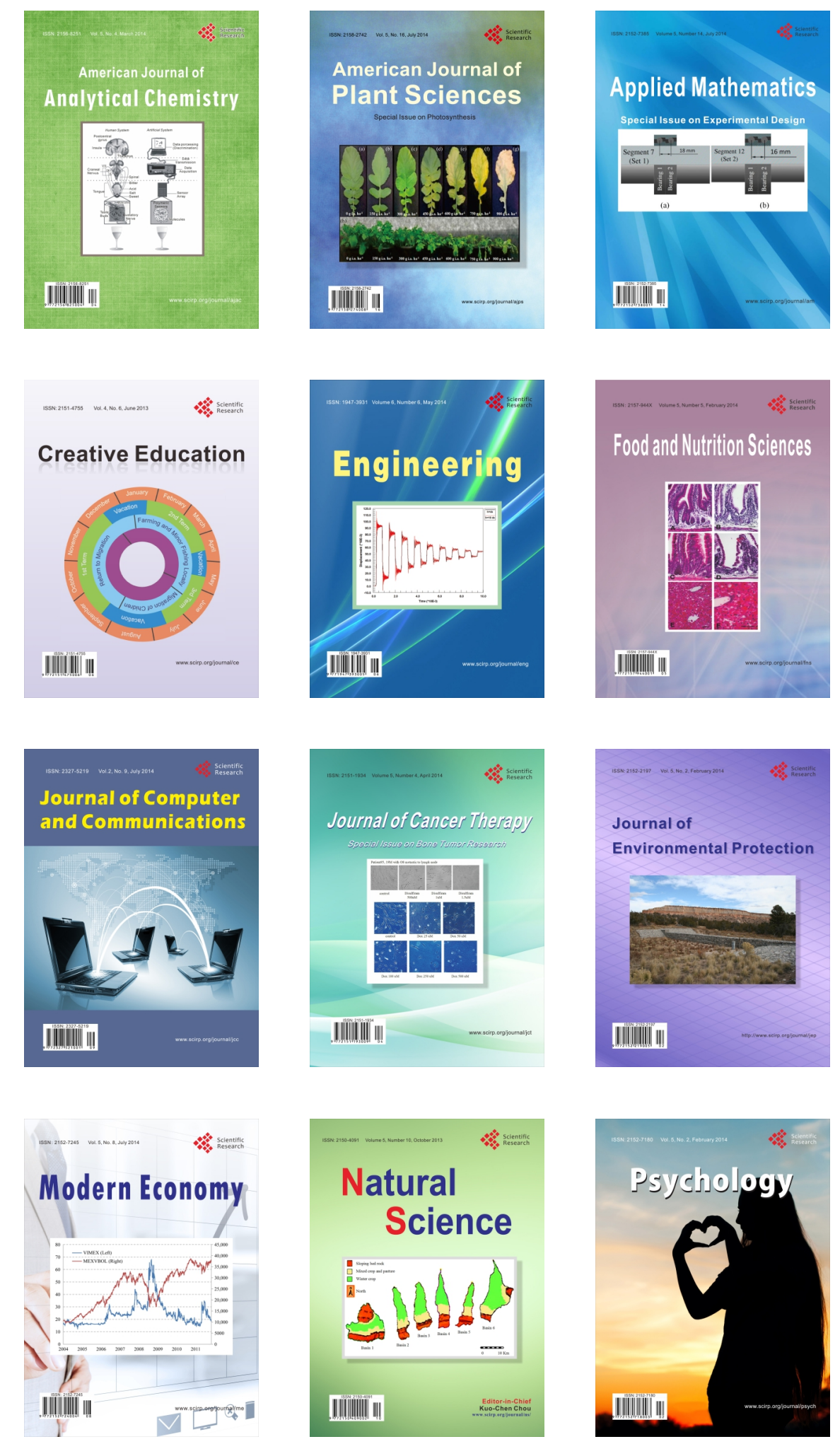